\title{
THE EFFECTS OF PRAGMATIC INSTRUCTION ON THE PRAGMATIC AWARENESS AND PRODUCTION OF KOREAN UNIUERSITY STUDENTS
}

\author{
Hyekyeng Kim \\ Kumoh National Institute of Technology \\ kimhk@kumoh.ac.kr
}

First received: 7 April 2017

Final proof received: 27 September 2017

\begin{abstract}
Despite the ongoing research of interlanguage pragmatics, intervention studies concerning pragmatic instruction have not been conducted as actively. The present study aims to investigate the effects of pragmatic instruction on Korean university students specifically regarding compliment responses. The effects of the instruction were examined in terms of the students' pragmatic awareness and production, according to the various language proficiency levels of the students. A total of 106 Korean university students from various majors participated in the study. The experimental group received explicit pragmatic instruction, which entailed metapragmatic instruction, awareness raising activities, and output practice regarding compliment responses, whereas the control group was exposed to the target features with no explicit instruction. A set of pragmatic awareness questionnaire and discourse completion tasks were administered as the data collection instruments and an eclectic design was adopted to analyze the effects of the instruction regarding their pragmatic awareness and production. The results indicate that explicit pragmatic instruction provided positive effects for raising the level of pragmatic awareness in the low group. Additionally, both the intermediate and low groups showed a significant improvement in production, as confirmed by the examination between and within subjects, and also displayed a range of formulaic expressions with a less idiosyncrasy attributed to first language transfer. These results call for further attention to pragmatics in second language (L2) teaching and learning.
\end{abstract}

Keywords: pragmatic instruction; pragmatic awareness; pragmatic production; compliment responses; linguistic proficiency

Due to a growing increase in international travel and interaction with people from diverse cultures and languages, it is not unusual to encounter L2 user's awkward or idiosyncratic phrases which might sound (unintentionally) rude or offensive to native English speakers, as was often noted in studies of second language (L2) pragmatics (e.g., Chen, 2009). An example of the differences in language use is that typical Asian responses to compliments mostly reject or downgrade compliments out of respect for the social value of modesty (Chen, 1993; Kim, 1998). This type of miscommunication, however, might put the interlocutors in an uncomfortable situation, or jeopardize the communication or even their future relationship as it may cause misunderstanding or discomfort with native English speakers (NSs) who are more likely to accept or return a compliment (Herbert, 1986, 1990; Holmes, 1988; Knapp et al., 1984). Given that pragmatic competence plays a major role in maintaining a conversation and ensures a concomitant relationship, it is essential to acquire pragmatic and intercultural knowledge about the target language and culture because responses to compliments have shown great variance across different cultures.

Early researches in pragmatics began in the 1970 s and were mostly based on the cross-cultural studies, which compared different language features between the learners' first language (L1) and the target language. Recently, the issue of teachability of L2 pragmatic features has begun to be proposed, based on which the effects of different types of pragmatic instruction have been further investigated with respect to a range of pragmatic features (e.g., Halenko \& Jones, 2011; House, 1996; Kasper \& Roever, 2005; Kim, 2015; Rose, 2005; Soler, 2005; Takahashi, 2001, 2005; Tateyama, 2001). These studies attempted to identify which type of instruction, among implicit instruction, explicit instruction, and simple exposure to input, would yield the best results for improvement of L2 pragmatic production. In Rose's (2005) metaanalysis of the effects of pragmatic instruction, it was revealed that explicit instruction was generally more effective in teaching L2 pragmatics.

Despite the growing body of research, little attention has been paid to the development of pragmatic awareness and production of EFL adult learners (for awareness, see Takahashi, 2015). Further, there is a paucity of intervention studies incorporating Asian learners with respect to teaching L2 pragmatics in the classroom settings. With regards to Korean students, most of the studies involving their L2 pragmatics have only analyzed the different uses of specific pragmatic features between NSs and Korean students, based on 
comparative studies, while only a few included pragmatic instructions and their effects on learners' performance. Additionally, compliment response has hardly been focused in the examination of L2 speech acts in spite of its unique properties inherited from an individual culture.

In this regard, the present study aims to account for the previous research gaps mentioned. This study will examine the effect of pragmatic instruction on Korean university students' pragmatic awareness as well as pragmatic production regarding English compliment responses. Additionally, it aims to compare the results between intermediate and low language proficiency groups. The findings of this study aim to offer some insights into teaching L2 pragmatics and draw attention to the intercultural aspects of teaching and learning a second language concerning the performance of speech acts.

\section{Previous studies of compliment responses}

The previous studies of compliment responses were researched with a major focus on cross-cultural studies to reveal distinctive differences among cultures. It was often investigated with the speech act of compliments as "an adjacency pair" (Schegloff \& Sacks 1973, p. 296) comparing the types of expressions depending on the interlocutor's status and different complimenting situations. Studies regarding compliment responses, in particular, have mostly analyzed response types and reported disparities in the expressions made by NSs and nonnative English speakers (NNSs).

The studies showed that native speakers of English tend to accept compliments given more frequently (e.g. "Thank you.") than nonnative English speakers who often reject (e.g. "It is worthless).") or deflect them (e.g. "My mom bought it for me.") (Han, 1992; Herbert, 1986, 1990; Holmes, 1988; Kim, 1998; Knapp et al., 1984; Sharifian, 2005). Knapp, Hopper and Bell (1984) examined 768 compliment responses elicited from Americans and discovered that more than half of the compliment responses employed a type of acceptance. Additionally, Holmes's (1988) study reported a high use of a type of acceptance is consistent results with those of Knapp et al. (1984). Along with this line, Herbert $(1986,1990)$ examined a large scale of data for the compliment responses and showed that $66 \%$ of American's responses were agreements. Further, Chen (1993) compared his data collected from Americans to the results of Holmes' study (1988) and noted that the number of compliment response types of accepting (39.28\%) and returning $(18.50 \%)$ in his study were nearly equivalent to Holmes' classification of acceptance-which includes 1. appreciation, 2. agreeing utterance, 3. downgrading, 4. return compliment - and showed a congruent tendency of the use of response types selected from the classification.

It is noteworthy that Asians showed a low acceptance for the given compliment. Chen's Chinese data displayed merely $1.03 \%$ for accepting compliments, which was noticeably different than the results of American's responses $(57.78 \%$ of accepting). Likewise, Han (1992) found through an investigation of interactions between Korean and American students that Korean students had a stronger tendency to reject or deflect the given compliments. Further, the students were found to be more likely to accept compliments in the interactions carried out in English rather than in Korean. Along with this line, Kim (1998) examined the role of pragmatic transfer based on the data of compliments and compliment responses. It was discovered that Korean ESL and EFL students showed a higher tendency of accepting or positively elaborating on the compliments in English as compared to the interactions carried out in Korean, but still less than American English speakers. Sharifian (2005) also investigated differences between Persian and Australian English speakers in terms of the notion of modesty or humbleness through compliment behavior. Sharifian revealed that Persian speakers were more likely to downgrade or return the compliments than Australian English speakers. It appeared that Asian speakers' low acceptance rate of compliment responses is attributed to their social norms due to variance in notions of modesty or humbleness across cultures.

Chen (1993) noted that Gu's (1990) politeness principle can elucidate nearly $99 \%$ of the Chinese speakers' responses to compliments given since his politeness principle reflects Chinese people's belief of living as a member of society. In fact, it appears probable that Gu's politeness principle could be applied to delineate the modes of speakers' compliment responses in other Asian countries including Korea and Japan as they share some similarities in culture regarding the concept of modesty, as seen in their responses to compliments as previously shown.

\section{The effects of the pragmatic instruction}

The early studies of interlanguage pragmatics were in large part based on comparative studies regarding specific speech acts or illocutionary meanings, describing the ways in which the realizations L2 students made were different from native English. However, with the influence of Schmidt's (1993) noticing hypothesis concerning the learning of L2 pragmatics and discourse, studies began to focus on the development of interlanguage pragmatics and were conducted in terms of the teachability of L2 pragmatic features including discourse markers and conversational routines, as well as speech acts. Along this line, the effects of various pedagogical interventions began to be examined, and specifically, 
implicit or explicit instructions were compared to determine their effectiveness as instructional tools for pragmatic language features. As for explicit instruction, it usually included a metapragmatic explanation or discussion designed to make the target pragmatic features more salient to L2 students, whereas implicit instruction was commonly delivered through enriched input containing the target features which students were expected to learn. In addition, the input was often given either with or without visual enhancement.

A majority of studies examining different pedagogical interventions indicated that students who received explicit instruction outperformed those who did not (e.g., Halenko \& Jones, 2011; House, 1996; Kasper \& Roever, 2005; Kasper \& Rose, 2002; Li, 2012; Morrow, 1996; Rose, 2005; Soler, 2005; Tajeddin \& Ghamari, 2011; Takahashi, 2001, 2005; Tateyama: 2001; Wildner-Bassetts, 1984; Yang, 2006). Several studies investigated the effects of implicit and explicit instruction concerning L2 pragmatic features, and positive outcomes from the explicit instruction were confirmed. Wildner-Bassetts (1984), for instance, compared the effects of implicit and explicit instructions in terms of the use of pragmatic features. The results demonstrated that the explicit group made more use of gambits to express (dis)agreement in a business context. Likewise, Tateyama (2001) investigated the effects of explicit and implicit teaching of pragmatic routines such as Japanese sumimasen to students enrolled in a Japanese class in America. The results were also in line with the previous studies, revealing that explicit instruction was more effective than implicit instruction in terms of the acquisition of L2 pragmatic routines, as the explicit group utilized routine expressions in authentic situations more frequently than did the implicit group. It is also noteworthy that although there was no statistical significance in the results of the implicit group, their responses entailed content which received higher scores in the evaluation of pragmatic routines than in the explicit group. In addition, the results from Tajeddin and Ghamari (2011) also showed that instruction of compliments and compliment responses was helpful for improving pragmatic competence for Farsi-speaking females.

Interventional studies that examined the development of pragmatic awareness have been rather scarce in comparison with those concerning pragmatic production. Nonetheless, the few studies which investigated learners' pragmatic awareness shared some similarities with the previous studies in terms of the positive effects of explicit pragmatic instruction (Halenko \& Jones, 2011; Liddicoat \& Crozet, 2001; Murray, 2010; Niezgoda \& Röver, 2001; Soler, 2005). Soler (2005) examined the effects of various pedagogical interventions on students' pragmatic awareness and pragmatic production by comparing three groups (explicit, implicit, and control), and discovered that the students benefited from both explicit and implicit instruction in terms of pragmatic awareness. However, the explicit instruction was found provided the students with more advantages in performing requesting strategies. In addition, Liddicoat and Crozet (2001) provided university students in Australia with a 10-week explicit instruction about French and examined the instructional effect and language retention through analyzing role-plays. The results from the immediate posttest showed that the students had developed pragmatic awareness of French cultural expectations as well as interactional norms. However, in the delayed posttest, students displayed similar content but with different forms with the responses from the immediate posttest, and further, they employed the identical forms which had appeared in the pretest.

Although there were some studies showing some inconsistent results with previous research concerning the effects of pragmatic instruction (e.g., Fukuya, Reeve, Gisi \& Christian, 1998; Kubota, 1995; Li, 2012; Rose \& Ng, 2001), the body of accumulative findings suggest that in general, explicit instruction helps learners to enhance L2 pragmatic competence better than implicit instruction or exposure to input. As Schmidt posited in his noticing hypothesis, instruction can help students better notice to which features they should pay attention. In this sense, it appears that explicit instruction facilitates the development of L2 pragmatics more effectively as it includes a metapragmatic explanation that can help students notice the target feature better, which theoretically leads to learning.

Based on the literature of interlanguage pragmatics concerning speech acts and instructional effects, the current study proposes the following questions:

1. Does pragmatic instruction affect the learners' pragmatic awareness regarding compliment responses? If so, are there any differences between the intermediate and the low groups?

2. Does pragmatic instruction affect the learners' pragmatic production regarding compliment responses? If so, are there any differences between the two groups?

3. How do the uses of pragmatic features of compliment responses from the instructed group of EFL university students differ from those of native English speakers?

\section{METHOD \\ Participants}

The total number of participants in the present study was 106 Korean students from a large university in 
Korea and 14 native English speakers from various countries. The students ranged in age from 20 to 27 years old. There were 58 female and 50 male students from various majors. The students were selected from four intact classes taught by the researcher of the current study. Among these four classes, two classes were assigned to the experimental group, and the other two as the control group. The students in each group were evaluated based on their oral ability by two raters, and no significant differences between the experimental and the control groups were detected, confirmed by an independent sample $t$-test $(p=.125$ for the intermediate group and $p=.147$ for the low group). Each group was divided into two levels of English proficiency, intermediate, and low, based on their oral interview score. Additionally, the students had received formal English education in Korea for 10 years, and those who had dissimilar educational background were checked through demographic questionnaire and were not included in the data analyses.

Further, 14 native English speakers participated in this study, and their responses served as the baseline data for comparison with the students' responses after receiving pragmatic instruction treatment. All the NSs were raised and educated in English speaking countries and were carefully selected to be of different nationalities (American, Australian, Canadian, and English) so as to gain valid data for accurate assessment of the situations provided in the DCT, as well as to diminish the pragmatic characteristics of a specific language community, if any. Table 1 displays the participants' information in this study.

Table 1. Participants

\begin{tabular}{lcccllc}
\hline & Intermediate & Low & Total & Nationality & Total \\
\hline Experimental group & 27 & 25 & 52 & \multirow{2}{*}{ Native Speakers } & $\begin{array}{l}\text { America, Australia, } \\
\text { Canada, England }\end{array}$ & 14 \\
\hline Control group & 25 & 29 & 54 & & Cann
\end{tabular}

\section{The procedure of the treatment}

The pragmatic instruction given as the treatment for the present study was designed to facilitate both the pragmatic awareness and the pragmatic production of the students concerning their compliment responses. The instruction entailed several activities adapted from suggested teaching techniques found in previous studies of interlanguage pragmatics (e.g., Kim, 2015; Li, 2012; Olshtain \& Cohen, 1991), such as dialogic assessments, evaluations of situations, input and output activities, metapragmatic explanations, role plays, and feedback. The pragmatic instruction in this study consisted of four sessions, each of which was provided for 30 minutes of regular class hours. It was provided twice a week for two weeks. The first two sessions were planned to improve the students' pragmatic awareness through delivering opportunities for metapragmatic explanation, video clips that included the target features, evaluation of a situation, and discussions with either peers or as a whole class. In addition, the third and fourth sessions focused on enhancing the students' production by providing various situations to perform the speech act and give feedback as well as role plays in which the use of the compliment responses was encouraged. On the other hand, the control group was only provided with abundant exposure to either visual or auditory materials that included the target features, but no explicit attention was drawn to the specific language.

\section{Data collection}

A combination of qualitative and quantitative data collection instruments were employed to obtain data for this study. A set of data collection instruments was administered twice, before and after the treatment, and the main data collection employed for the study was the pragmatic awareness questionnaire (PAQ) and the discourse completion task (DCT) which were created for this study. The PAQ was developed based on the previous studies of interlanguage pragmatics (e.g., Bardovi-Harlig \& Dörnyei, 1998; Bardovi-Harlig \& Griffin, 2005; Halenko \& Jones, 2011; Niezgoda \& Röver, 2001; Schauer, 2006), and its reliability was confirmed through Cronbach's alpha (0.71). It consisted of eight utterances with underlined expressions which the participants assessed for pragmatic appropriateness. In order to avoid the priming effect, two questions were asked about unrelated speech acts. The PAQ was constructed on the basis of a four-point Likert-scale with semantic differentials.

Additionally, a DCT was developed to gather students' actual production concerning the compliment responses and its reliability was also confirmed (Cronbach's alpha, 0.86). It was composed of eight situations in which six questions asked the students to respond to compliments given, and two were directed the students giving compliments. After the DCT was collected, the participants' responses were evaluated on a fivepoint scale by two native English speakers based on a provided scoring rubric. An in-depth qualitative analysis of the responses was then conducted to examine the expressions and types of compliment responses.

\section{Data coding and analysis}

In order to identify differences in the realization patterns of compliment responses between the instructed group and native speakers, as well as 
between the intermediate and the low language proficiency groups, the responses on the DCT were divided into four types: accepting, returning, deflecting or evading, and rejecting. This division of compliment responses utilized in this study was adopted from Holmes (1988) as it best represented the categories for the data of this study. The major types of the patterns for compliment response are presented in Table 2. The responses were categorized by two coders (the researcher and one of the native English speakers who rated the DCT) after they had a workshop and a few practice sessions. Inter-coder agreement was tested and it indicates a high level of agreement, $96 \%$.

Table 2. Classification of Compliment Responses

\begin{tabular}{ll}
\hline Accepting & 1. Thanking, 2. Agreeing, 3. Expressing gladness, 4. Joking \\
\hline \multirow{2}{*}{ Returning } & $\begin{array}{l}\text { 5. Returning compliment, 6. Offering object of compliment, } \\
\text { 7. Encouraging }\end{array}$ \\
\hline \multirow{2}{*}{ Deflecting } & $\begin{array}{l}\text { 8. Shifting credit, 9. Informative comment or evading, } \\
\text { 10. Legitimate evasion, 11. Doubting }\end{array}$ \\
\hline Rejecting & 12. Rejecting and denigrating \\
\hline
\end{tabular}

The content of the DCT responses was examined in depth based on the approach of grounded theory. In order to uncover emerging themes, three phases of coding--open coding, axial coding, and selective coding--were employed as suggested by Dörnyei (2007). Through these processes, this study investigated the students' responses in terms of the frequency of use of formulaic expressions and negative L1 transfer.

As for the quantitative analysis, the data gathered from PAQ and the mean scores of the responses from the DCT were analyzed using a paired $t$-test and an independent sample $t$-test for the examination within subjects and between subjects. In addition, the responses from the DCT were scored on a five-point scale by the two raters based on a rubric that was adapted from the TOEFL scoring standards and the guidelines of the evaluation for speaking provided by the American Council on the Teaching of Foreign Languages (ACTFL 2012). The Pearson's $r$ results demonstrated a considerably high interrater reliability between the two raters (Pearson's $r=.78$ ).

\section{RESULTS AND DISCUSSION}

The effects of the pragmatic instruction on the students' pragmatic awareness

To examine the effect of the explicit pragmatic instruction between subjects, an independent sample $t$-test was conducted with the gain scores of the PAQ. The results indicated that there was a statistically significant difference in the increase of gain scores of the learners' pragmatic awareness between the experimental and control groups $(t[104]=4.448$, $\left.p=.000^{* * *}\right)$, as shown in Table 3. Furthermore, a paired-sample $t$-test was also conducted to examine the differences of mean scores within subjects. The analysis revealed that the experimental group displayed significant improvement in their scores from the pretest to the posttest $(t[51]=-2.751$, $p=.008^{* *}$ ) while the control group did not show any increase in their mean score.

Table 3. Summary of Independent Sample $t$-tests for PAQ

\begin{tabular}{|c|c|c|c|c|c|c|}
\hline Level & Group & M & SD & $T$ & $d f$ & $p$ \\
\hline \multirow[t]{2}{*}{ Mixed } & Experimental & 0.08 & 0.21 & 4.448 & 104 & $.000 * * *$ \\
\hline & Control & -0.15 & 0.30 & & & \\
\hline \multirow[t]{2}{*}{ Intermediate } & Experimental & 0.05 & 0.21 & -1.697 & 50 & .098 \\
\hline & Control & -0.08 & 0.32 & & & \\
\hline \multirow[t]{2}{*}{ Low } & Experimental & 0.12 & 0.22 & 4.621 & 52 & $.000 * * *$ \\
\hline & Control & -0.20 & 0.28 & & & \\
\hline
\end{tabular}

These results were congruent with the findings of previous studies with regard to the positive effects that explicit pragmatic instruction had on enhancing the students' pragmatic awareness (Halenko \& Jones, 2011; Liddicoat \& Crozet, 2001; Murray, 2010; Niezgoda \& Röver, 2001; Soler, 2005;). Supporting the results from Kasper and Rose (2005), explicit pragmatic instruction in this study yielded positive effects for developing pragmatic awareness in an EFL classroom setting, without residing in an English speaking environment. This positive instructional effect appeared to be based on the noticing hypothesis in which Schmidt (1993) argued that input can be intake if the target feature is noticed by learners. The instruction that served as treatment in this study intentionally included awareness raising activities, which seemed to help the students notice the target features regarding the sociopragmatic and pragmalinguistic features of compliment responses.

In order to analyze the scores according to the participants' language proficiency levels, the identical methods of statistical analyses were conducted for both groups. It was revealed that the results concerning the intermediate level students were not consistent with the findings of some 
previous studies including the students at the intermediate level (e.g., Langer, 2011; Martínez-Flor \& Soler, 2007). Langer noted that the intermediate level group seemed to be the optimal stage for improving L2 pragmatics based on their performance in comparison with the advanced and low levels in her study. However, the result of this study showed that there was no significant difference in the gain scores between the experimental and the control groups $(t[50]=-1.697$, $p=.098)$. Moreover, even though their mean score improved from the pretest to the posttest with an increase of 0.05 points, a paired $t$-test confirmed that the increase of mean score was not significant $(t[26]$ $=-1.154, p=0.259)$. It was shown that the explicit pragmatic instruction did not aid the students at the intermediate level in raising their level of pragmatic awareness. These results seem to be attributed to the simplicity and transparency of the expressions used as compliment responses. This was also seen in Rose and Ng's (2001) study regarding the speech act of compliments. They noted that the participants in their study were advanced students who might not require further improvement as complimenting expressions are normally syntactically and lexically straightforward. In this regard, the students in the intermediate level group in this study also appeared to have selected the appropriate expression with ease likely due to the simplicity of these expressions.

In contrast with the results of the intermediate level group, the pragmatic instruction proved to be highly effective for the students in the low proficiency level group. These results shared similarities with groups in previous research regarding the positive effects of pragmatic instruction on students in low language proficiency levels (e.g., Li, 2012; Tateyama, 2001; Yang, 2006). There was a significant difference in the gain scores between subjects, as confirmed by an independent sample $t$-test $(t[52]=4.621, p=.000 * * *)$. Also, their mean score increased by 0.12 points from 0.47 for the pretest to 0.59 for the posttest, and a paired $t$-test indicated that the increase of their mean score was significant $\left(t[24]=-2.753, p=.011^{*}\right)$. These results demonstrate that the overall statistical significance shown for the effects of pragmatic awareness instruction can be attributed to the increase made by the students at the low level. The positive effects seen from the pragmatic instruction on the low group are thought to be the result of the transparent and simple aspects of the expressions. That is to say, the expressions for compliment responses were quite simple both syntactically and lexically, and are thus at an appropriate level for the low group to learn the target features. Additionally, since they are quite routinized and formulaic, it appeared not to be challenging even for the low proficiency level students to identify the appropriate expressions after receiving the pragmatic instruction. However, as these expressions are quite simple and likely to be acquired, it seemed that the intermediate level group already had a higher level of awareness and ability and thus less area to improve.

Taken as a whole, the pragmatic instruction was facilitative in enhancing the pragmatic awareness of the students in the low proficiency level with regard to compliment responses. The intermediate proficiency level group displayed an increase in their mean score from pretest to posttest, but the statistics showed that there was no significance for the examination between subjects and within subjects. The results for both groups are attributed to the syntactic and lexical simplicity of the expressions for compliment responses. The intermediate group were likely to select the appropriate expressions without difficulty before the treatment, and the low group was able to effectively learn the necessary pragmalinguistic and sociopragmatic knowledge after the treatment.

\section{The effect of the pragmatic instruction on the} students' pragmatic production

To analyze the effects of pragmatic instruction between subjects, an independent sample $t$-test was performed on the gain scores from the DCT. The results showed that there was a significant difference in the gain scores between the experimental and the control groups $(t[104]=3.948$, $p=.000 * * *)$. For the comparison of the scores within subjects, a paired-sample $t$-test was conducted and revealed that the difference in gain scores from the pretest to the posttest were statistically significant $\left(t[51]=-2.257, p=.028^{*}\right)$ whereas the increase that control group made was not significant $(t[53]=-$ $1.382, p=.173)$. It demonstrates that the explicit pragmatic instruction facilitated an improvement in the students' production of pragmatically appropriate expressions in terms of compliment responses.

Furthermore, the analyses of the scores from both proficiency levels showed that the students in both the intermediate and low levels had a statistically significant difference in the gain scores for their pragmatic production between the experimental and the control groups. An independent sample $t$-test showed $t[50]=2.051$, $p=.046^{*}$ for the intermediate group and $t[52]=3.542$, $p=.001^{* *}$ for the low group. The experimental groups in both proficiency level groups also showed significant improvement in their mean scores from the pretest to the posttest $(t[26]=-2.846, p=.009 * *$ for the intermediate group and $t[24]=-3.076$, $p=.005^{* *}$ for the low group). These results are different from previous results concerning pragmatic awareness in that the explicit pragmatic instruction in this study enhanced pragmatic production for the students from both levels. The statistical information is summarized in Table 4 and Table 5.

As Bardovi-Harlig and Dörnyei (1998) noted, grammatical competence does not ensure an 
equivalent degree of pragmatic competence even for the students in ESL environments, let alone for those in EFL settings who have limited exposure to L2 pragmatic examples or rules. This phenomenon was confirmed in the pretest in which the students from the intermediate level displayed plenty of idiosyncratic expressions. This idiosyncrasy appeared to be attributed to negative L1 transfer as these types of the expressions are frequently observed in casual Korean conversation among Korean college students, albeit further to be documented. Also, the participants in this study have not lived in English speaking countries before and have received limited exposure to formulaic expressions on account of EFL context.

Table 4. Summary of Paired Sample $t$-tests for DCT

\begin{tabular}{|c|c|c|c|c|c|c|}
\hline Level & Group & $\mathbf{M}$ & SD & $T$ & $d f$ & $p$ \\
\hline \multirow[t]{2}{*}{ Mixed } & Pretest & 3.59 & 0.67 & -2.257 & 51 & $.028 *$ \\
\hline & Posttest & 3.83 & 0.57 & & & \\
\hline Intermediate & Posttest & 3.83 & 0.62 & & & \\
\hline \multirow[t]{2}{*}{ Low } & Pretest & 2.98 & 0.86 & -3.076 & 24 & $.005^{* *}$ \\
\hline & Posttest & 3.45 & 0.60 & & & \\
\hline
\end{tabular}

Table 5. Summary of Independent Sample $t$-tests for DCT

\begin{tabular}{|c|c|c|c|c|c|c|}
\hline Level & Group & $\mathbf{M}$ & SD & $T$ & $d f$ & $p$ \\
\hline \multirow[t]{2}{*}{ Mixed } & Pretest & 0.45 & 0.78 & 3.948 & 104 & $.000 * * *$ \\
\hline & Posttest & -0.07 & 0.60 & & & \\
\hline Intermediate & Posttest & 0.02 & 0.66 & & & \\
\hline \multirow[t]{2}{*}{ Low } & Pretest & 0.47 & 0.76 & 3.542 & 52 & $.001 * *$ \\
\hline & Posttest & -0.16 & 0.53 & & & \\
\hline
\end{tabular}

As an example, many of the students responded to a given compliment in a playful way, which is common among young Koreans, by expressing their affection to the person who complimented or offering to treat them for the gratitude for the given compliment, whereas the polite, typical way to respond to the compliment in Korea is normally by deflecting or rejecting it, saying: "Oh, it is worthless" or "This is actually not really good". The following are some excerpts from the students' performances:

(e.g. 1) A: Your dress looks great today! (excerpted from the pretest, 11)

B: Oh! I love you so much. (excerpted from the posttest,11)

(e.g. 2) A: Your cell phone looks very nice! (excerpted from pretest, 26 )

B: What do you want to eat? (excerpted from posttest, 26)

Nevertheless, after receiving the treatment, the students in both the intermediate and low proficiency level groups showed an improvement in their expressions of compliment responses. Idiosyncratic expressions were seldom found, and a number of the formulaic expressions introduced during the instruction were also employed in the posttest. Further, the students at the intermediate level showed almost native-like expressions of compliment responses after the instruction as the posttest contained very few idiosyncratic phrases that were resulted from L1 transfer. Further, a range of expressions for compliment responses were utilized, such as "Oh, thank you”, "It's nothing", "I'm glad you think so", "Yours looks great, too", "Yeah, I really like it", etc. Also, the total number of different expressions adopted was higher (from 254 to 274 expressions), and a series of expressions were employed for making compliment responses, such as "Oh, thank you. But it is nothing. But I am glad you think so", "Thank you. I really like it, too", and "Thank you. It's my pleasure." Additionally, the students in the low proficiency level group displayed a stronger tendency for returning the compliments, showing an increase in the use of Type 2, returning, from $9.7 \%$ to $20.3 \%$ after the instruction. Also, they displayed fewer grammatical mistakes in the posttest by employing formulaic expressions as taught in their classes. Nonetheless, they did tend to use a few formulaic expressions repeatedly, which is considered to be due to a limitation of their linguistic facility to apply the instructed expressions in only constrained ways.

In addition, the investigation into the experimental group's use of the categories of compliment responses demonstrated a considerable degree of similarity with those of the NSs. The students employed Type 1, accepting, most frequently, which accounted for $56.9 \%$ of their answers, followed by Type 2, returning, (18.1\%) and Type 3, deflecting, (16.8\%) in the posttest. Similar to these results, Type 1 composed $63.4 \%$ of the total responses by the NSs, Type 3 was $21.1 \%$, and Type 2 was $15.5 \%$. Also, it was conspicuous that in their responses the NSs made no use of Type (4), rejecting, but $7.9 \%$ of the compliment responses made by the students were categorized as rejecting 
in the pretest, with a similar amount still employed in the posttest.

It is noteworthy that a large group of students still employed the response type of rejecting the compliment in the posttest even though the NSs had no instance of use. Negating a given compliment is commonly found in Korean compliment responses as the notion of modesty is highly valued in Korean society. Supporting this, Chen (1993) showed that the manner of Chinese compliment responses follows the polite principle suggested by Gu (1990); this is similar in Korean culture as Koreans do not tend to praise themselves by accepting the compliments, and this cultural aspect accounts for the displayed expressions. An example of this is that 20 responses were categorized under Type (4) rejecting in the pretest, showing direct negation to the compliment given; nonetheless, the same type of responses was still employed in the posttest, but followed a routinized pattern of compliment responses as instructed. Some examples are as follows.

\section{e.g. 3) No, no this is very bad cell phone, just many kind of features. (excerpted from pretest, 46) \\ Oh, thank you. But it's nothing. Your phone is very} nice, too (excerpted from posttest, 46).

\section{e.g. 4) No, really ? I don't think so. (excerpted from pretest, 46) \\ Oh, thank you. But it is nothing. But I am glad you think so. (excerpted from pretest, 46)}

It is likely that the students attempted to adopt the pragmatic rules learned in creating their responses as shown in their lengthy expressions of compliment responses. However, it also seems apparent that the social values of modesty and politeness, which exert a great influence on their manner of communication in L1, were reflected in their responses. As Beebe, Takahashi, and UlissWeltz (1990) pointed out, the deeply embedded cultural value was hard to abandon even if they were aware of the different pragmatic rules between L1 and L2. Kim (1998) also discovered this aspect in her examination of Korean language transfer in complimenting and responding to compliments, noting that it represented the students' cultural identity as well as the degree of their socio-cultural adaptation to the L2 speech community.

Also, it was notable that the students in the low proficiency group increased their use of Type (2) responses, returning, after the instruction, resulting in $11 \%$ to $18.1 \%$ of their responses. It is estimated that the frequent use of Type (2) responses was attributed to the main example of the returning expressions, "Thank you", which is already wellknown to the students. This familiarity might have led the low proficiency group to utilize it more commonly in the posttest.

To summarize, the students in both the intermediate and low proficiency level groups showed significant improvement in pragmatic production regarding compliment responses. Both groups employed routinized and formulaic expressions more regularly in the posttest which led to a decrease in pragmatic and grammatical mistakes made. The consequence of these reductions in produced mistakes was that their responses were evaluated to be grammatically and pragmatically more appropriate to the situations.

\section{Conclusions and pedagogical implications}

The main purpose of this study was to investigate the effects of pragmatic instruction on the pragmatic awareness and production of Korean university students. The results were also examined to see if there is a difference in the effects of instruction according to different language proficiency levels. The experimental group received explicit pragmatic instruction in terms of sociopragmatic and pragmalinguistic aspects of compliment responses, while the control group was only exposed to the target features. In order to obtain the appropriate data, a PAQ and a DCT were created and administered before and after the treatment. From the analysis of research question 1 which aimed to investigate pragmatic awareness, it was found that pragmatic instruction yielded positive effects on raising the students' pragmatic awareness. However, statistical significance was found only in the results from the students in the low proficiency level group with regards to both within and between subject examinations. It is estimated that the students in the intermediate language proficiency level group showed minimal change from pretest to posttest as they did not have difficulty in choosing the appropriate expression in the pretest on account of the lexical and syntactic simplicity of compliment response expressions.

As for the analysis for research question 2 which aimed to investigate pragmatic production, pragmatic instruction was discovered to have provided positive effects on improving the students' pragmatic production. Unlike the results regarding pragmatic awareness, the intermediate group as well as the low group displayed a statistically significant difference in their gain scores between the experimental and the control groups. Also, both groups improved their mean scores from the pretest to the posttest, which was further proven to be statistically significant. Qualitative analysis also found that the students made more appropriate expressions according to L2 pragmatic rules after receiving pragmatic instruction. It was noted that idiosyncratic expressions resulting from L1 negative transfer were frequently discovered in the pretest, while the experimental group employed a variety of the instructed expressions for compliment responses in the posttest. The intermediate proficiency group utilized a range of expressions, and the low proficiency group repeatedly employed several 
formulaic expressions and thus displayed fewer grammatical mistakes. In addition, the distribution of compliment response types found in the posttest shared similarities with those made by NSs--most notably Type 1 responses, accepting, Type (2) returning, and Type (3) deflecting all showing a similar proportion. Nevertheless, although NSs did not employ Type (4), rejecting, at all, the students still used it along with other types of compliment responses. It is believed that the sociocultural value of modesty in the native culture of the students was carried over to their responses despite being aware of different pragmatic rules. Overall, explicit pragmatic instruction helped facilitate the Korean students' pragmatic awareness as well as production regarding compliment responses. However, it should be noted that the effect of the instruction may differ depending on the learners' individual differences as well as the difficulty of the target pragmatic features.

The results of the present study indicate some necessity of pragmatic instruction regarding compliments and compliment responses as they play an important role in social interaction and usually initiate conversation. It was seen in the previous research that typical Asian responses to compliments include rejecting or downgrading the compliment, and this may lead to miscommunication with native English speakers who are unaware of the speaker's cultural ethos. This situation might jeopardize a potential relationship and it is thus important to teach and learn pragmatic rules in order to build intimacy and relationships with those from the target language community. More detailed and extensive research on various speech acts as well as pragmatic features should be conducted with learners in diverse settings. Also, it would be beneficial to create materials for teaching and learning about English pragmatic rules, including compliment and compliment responses, based on the compiled findings to rectify a void in EFL English learning community. Further, as Kasper and Rose (2002) underscored the role of instruction regarding pragmatics in the L2 classroom and noted that L2 classrooms should aim to provide varying social contexts for developing students' pragmatic ability, more studies regarding different instructional interventions should be conducted.

\section{ACKNOWLEDGMENT}

Kumoh National Insitute of Technology is grafetully acknowledged for supporting the research

\section{REFERENCES}

Bardovi-Harlig, K., \& Dörnyei, Z. (1998). Do language learners recognize pragmatic violations? Pragmatic versus grammatical awareness in instructed L2 learning. TESOL
Quarterly, 32(2), 233-259. doi: $10.2307 / 3587583$

Bardovi-Harlig, K., \& Griffin, R. (2005). L2 pragmatic awareness: Evidence from the ESL classroom. System, 33(3), 401-15.

Beebe, L., Takahashi, T., \& Uliss-Weltz, R. (1990). Pragmatic transfer in ESL refusals. In R. C. Scarcella, E. Anderson, \& S. C. Krashen (Eds.), Developing communicative competence in a second language (pp. 55-73). New York: Newbury House.

Chen, R. (1993). Responding to compliments: A contrastive study of politeness strategies between American English and Chinese speakers. Journal of Pragmatics, 20, 49-75.

Chen, Y. (2009). Learner perceptions of instruction in L2 pragmatics. English Language Teaching, 2(4), 154-161.

Dörnyei, Z. (2007). Research Methods in Applied Linguistics. Oxford: Oxford University Press.

Fukuya, Y., Reeve, M., Gisi, J., \& Christian, M. (1998). Does focus on form work for sociopragmatics? Paper presented at the $12^{\text {th }}$ Annual International Conference on Pragmatics and Language Learning. University of Illinois, Urbana-Champaign.

$\mathrm{Gu}$, Y. (1990). Politeness phenomenon in modern Chinese. Journal of Pragmatics, 14, 237-257.

Halenko, N., \& Jones, C. (2011). Teaching pragmatic awareness of spoken requests to Chinese EAP students in the UK: Is explicit instruction effective? System, 39, 240-250.

Han, C. (1992). A comparative study of compliment responses: Korean females in Korean interaction and English interactions. Penn Working Papers in Educational Linguistics, 8(2), 17-31.

Herbert, K. (1986). Say "thank you” or something. American Speech, 61(1), 76-88.

Herbert, R. K. (1990). Sex-based differences in compliment behavior. Language in Society, 19, 201-224.

Holmes, J. (1988). Compliments and compliment responses in New Zealand English. Anthropological Linguistics, 28(4), 485-508.

House, J. (1996). Developing pragmatic fluency in English as a foreign language: routines and metapragmatic awareness. Studies in Second Language Acquisition, 18, 225-252.

Kasper, G., \& Roever, C. (2005). Pragmatics in second language learning. In E. Hinkel (Ed.), Handbook of Research in Second Language Teaching and Learning (pp. 317-334). Mahwah: Lawrence Erlbaum.

Kasper, G., \& Rose, K. R. (2002). Pragmatic development in a second Language. Malden: Blackwell.

Kim, Y. S. (1998). Pragmatic transfer in complimenting and responding to compliments by Korean learners of English. Journal of the 
Applied Linguistics Association of Korea, 14(2), 1-20.

Kim. H. K. (2015). The effects of pragmatic instruction on Korean university students with different language proficiency levels. Unpublished Doctoral Dissertation. Hankuk University of Foreign Studies, Seoul.

Knapp, M. L., Hopper, R., \& Bell, R. A. (1984). Compliments: A descriptive taxonomy. Journal of Communication, 34(4), 12-31.

Kubota, M. (1995). Teachability of conversational implicature to Japanese EFL students. IRLT Bulletin, 9, 35-67.

Langer, B. D. 2011. The effects of pragmatic instruction in the Spanish language classroom. Unpublished Doctoral Dissertation. University of California, Davis.

Li, Q. (2012). Effects of instruction in adolescent beginners' acquisition of request modification. TESOL Quarterly, 46(1), 30-55.

Liddicoat, A. J., \& Crozet, C. (2001). Acquiring French interactional norms through instruction. In K. Rose, \& G. Kasper (Eds.), Pragmatics in language teaching (pp. 125-144). Cambridge: Cambridge University Press.

Martínez-Flor. A., \& Soler, E. A. (2007). Developing pragmatic awareness of suggestions in the EFL classroom: A focus on instructional effects. Canadian Journal of Applied Linguistics, 10(1), 47-75.

Morrow, C. (1996). The pragmatic effects of instruction on ESL students ' production of complaint and refusal speech acts. Unpublished doctoral dissertation. State University of New York, Buffalo, New York.

Murray, N. (2010). Pragmatics, awareness raising, and the cooperative principle. ELT Journal, 64(3), 293-301.

Niezgoda, K., \& Röver. C. (2001). Pragmatic and grammatical awareness: A function of the learning environment? In K. Rose, \& G. Kasper (Eds.), Pragmatics in language teaching (pp. 63-79). Cambridge: Cambridge University Press.

Olshtain, E., \& Cohen, A. D. (1991). Teaching speech behavior to nonnative speakers. In M. Celce-Murcia (Ed.), Teaching English as a second or foreign language. New York: Newbury House.

Rose, K. R. (2005). On the effects of instruction in second language pragmatics. System, 33, 385399.
Rose, K. R., \& Ng. C. (2001). Teaching compliments and compliment responses. In $\mathrm{K}$. Rose, \& G. Kasper (Eds.), Pragmatics in language teaching (pp.145-170). Cambridge: Cambridge University Press.

Schauer, G. A. (2006). Pragmatic awareness in ESL and EFL contexts: Contrast and development. Language Learning, 56(2), 269-318.

Schegloff, E. A., \& Sacks, H. (1973). Opening up closings. Semiotica, 8(4), 289-327.

Schmidt, R. (1993). Consciousness, learning and interlanguage pragmatics. In G. Kasper, \& S. Blum-Kulka (Eds.), Interlanguage pragmatics. Oxford: Oxford University Press.

Sharifian, F. (2005). The Persian cultural schema of Shekastehnafsi: A study in compliment responses in Persian and Anglo Australian speakers. Pragmatics and Cognition, 13(2), 338-361.

Soler, E. A. (2005). Does instruction work for learning L2 pragmatics in the EFL context? System, 33, 417-435.

Tajeddin, Z., \& Ghamari, M. R. (2011). The Effect of Instruction in Pragmatics: Compliments \& Compliment Responses. Theory and Practice in Language Studies, 1(9), 1078-1090.

Takahashi, S. (2001). Input enhancement in developing pragmatic competence. In K. Rose, \& G. Kasper (Eds.), Pragmatics in language teaching (pp. 171-199). Cambridge: Cambridge University Press.

Takahashi, S. (2005). Noticing in task performance and learning outcomes: A qualitative analysis of instructional effects in interlanguage pragmatics. System, 33, 437-461.

Takahashi, S. (2015). The effects of learner profiles on pragmalinguistic awareness and learning, System, 48, 48-61.

Tateyama, Y. (2001). Explicit and implicit teaching of pragmatic routines: Japanese sumimasen. In K. Rose, \& G. Kasper (Eds.), Pragmatics in language teaching (pp. 200-222). Cambridge: Cambridge University Press.

Wildner-Bassetts, M. (1984). Improving Pragmatic Aspects of Students' Interlanguage. Narr: Tübingen.

Yang, E. M. (2006). Effects of instructional intervention in low-level college students' learning of request acts. English Language \& Literature Teaching, 12(2), 215-235. 